All things considered, the lawsuit from the US administration could not have come at a worse time. The green biotech industry is in tatters, public sensitivities are outraged and GM technology has become further allied to economic and political imperialism. GM products can scarcely fall in popularity, but it seems that they will if the USA wins and gets its produce onto European supermarket shelves. But the USA is unlikely to be a contented winner. "W hat the USA is doing in trying to force GMOs into Europe will achieve the contrary of what is intended," Potrykus said. The very act of labelling them and allowing the public a choice is likely to herald their demise, and the demise too of European GM products that try to make it to market. As the EC source remarked, with some chagrin, "The whole issue is whether big supermarkets will take the risk of putting GM products on their shelves; they will take a risk for sure."

But there is another reason why the USA may not be smiling for long if it wins its case at the WTO. Ironically, not long after the case was filed, a long process of negotiations, held in Washington, DC, between the agribiotech industry and its critics concerning regulations, ended in stalemate. The process, known as the Pew discussions, involved, among others, representatives from Monsanto (St Louis, MO, USA) and consumer and public interest groups that are critical of what they consider to be poor federal regulation of the industry. The US Food and Drug Administration operates a voluntary system in which biotech companies dictate their own product-safety tests, without the need to submit full data. Some now speculate that food companies, nervous about public acceptance of GM food, could lobby congress for tighter regulations, bypassing the likes of Monsanto.

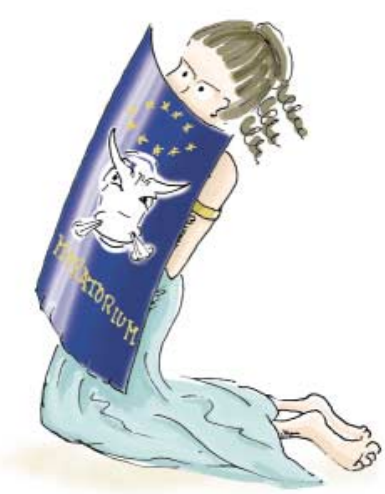

The alternative may be for food companies to avoid certain biotech crops-such as GM wheat- that are unlikely to perform in foreign markets resistant to GM products. Finally, the lawsuit itself could become an embarrassment for the WTO, whose woolly rules are not suitable for dealing with a case of such scientific and political complexity.
Whatever the short-term outcome of the present transatlantic squabble, the USA and the EU will face a future that requires even more deftness in handling public concerns than is the case at present.

\section{Andrew Moore}

doi:10.1038/sj.embor.embor894

\title{
Health is a global issue
}

\author{
TheSARS epidemic was a wake- up call for public health authorities \\ worldwideabout the threat of emerging infectious diseases
}

\section{T}

he concerted international publichealth initiative to stem the global spread of Severe Acute Respiratory Syndrome (SARS) seemed to be paying off in late $M$ ay. After waxing and waning, infection and death rates were steadily falling in most affected areas, and the World Health Organization (WHO) lifted some of their travel warnings. The crippled Asian stock market also began to rebound for the first time since the Chinese authorities reported the disease to the WHO in early February. As of 29 May, 8,295 people in 30 countries have been reported to be infected with SARS and the disease had claimed at least 750 lives. SARS, the first severe and contagious new disease to emerge in the twentyfirst century, was a crude and widely heard wake-up call for societies and authorities worldwide about the threat of infectious diseases in an era of global trade and travel. But seeing it from a more long-term perspective, SARS is only the thirtieth new disease identified during the past 30 years, as $\mathrm{N}$ oel J. Snell from the Imperial College School of Medicine in London, UK, noted in Drug Discovery Today $(\mathbf{8}, 22-30 ; 2003)$.

The SARS epidemic is, however, not over at the time of writing, nor is the fear it created-many people in Asia and at international airports are still wearing face masks. A new increase in SARS cases in Toronto, Canada, at the end of May tripled the tally in the city to 33 new probable victims, and the local authorities initiated new quarantine measures. Together with questions about the veracity of China's reports about falling SARS rates, the new cluster of patients in Toronto tempered any guarded optimism that the epidemic was coming to an end. Nevertheless, scientists and public health officials had already made significant progress in fighting a disease that seemingly came from nowhere. A combination of new high-tech diagnostic methods and traditional low-tech quarantine measures helped to quickly contain SARS in many countries. Rapid DNA sequencing to diagnose the virus causing SARS and the use of infrared cameras at Asian airports to check passengers for fever prevented its further spread over international borders. A study of 1,425 patients in Hong Kong, China, also confirmed the efficacy of contact tracing, quarantining and passenger screening. It revealed that efforts to reduce the time from symptom onset to quarantine in a hospital was one of the most important public health measures in reducing disease transmission, noted one of its authors, Roy Anderson, Professor of Epidemiology and Infectious Diseases at London's Imperial College (Lancet, 361, 1761; 2003).

Indeed, at the beginning of June, it looked like SARS would be limited to China and Toronto. Initial cases in France, Germany, the UK and the USA earlier this year were relatively few and were quickly contained. Rapid action by the Vietnamese government also quickly rooted out the disease there, and Singapore seems to have been lucky as well. The Chinese government also became increasingly clear about the extent of the disease, and removed the Chinese health minister and the Mayor of Beijing in A pril, largely because they and others had tried to sweep the epidemic under the carpet last winter. 


\section{science $\&$ society}

S ience has had its share in this success as well. The fact that scientists identified and sequenced the corona virus that causes SARS in record time-just over a month-by international collaboration, not competition, "is almost unprecedented," said Maria Zambon, Deputy Director of the Enteric, Respiratory, and Neurological Virus Laboratory at the UK's Health Protection Agency in London. "In this globalized world, such collaboration is the only way forward in tackling emerging diseases," commented Klaus Stohr, WHO coordinator of the SARS research team. By late May, researchers had also discovered the virus in three wild animal species-civet, raccoon dog and the Chinese ferret badger-in southern China's Guangdong province, where the disease originated in November 2002 . This finding provides further evidence for the theory that the virus, which had not been seen before, jumped from these species to humans. Scientists then found antibodies against the virus in individuals who worked in a Guangdong market; surprisingly, these individuals were infected but did not fall ill.

\section{The SARS outbreak has also been a major test of theW $\mathrm{H} O$ 's ability to deal with emerging infectious diseases and, on most accounts, it has scored well}

On the basis of these findings, many scientists now believe that it could be difficult to totally eradicate SARS because it has an animal reservoir and may be affected by seasonal temperature changes. Efforts to clean up the Guangdong animal market and the Chinese government's warnings against consuming wild animals and spitting in public may be helpful, but long-held cultural habits do not change overnight. Furthermore, international travel is still a wildcard when it comes to infectious diseases such as SARS. "There is no clear end in sight," said Zambon. Public-health officials were at first hopeful that SARS could be arrested in China as it had been in Vietnam, but they are now less optimistic because of the sheer size of the nation, said Bernhard Fleischer from the Bernhard-Nocht Institute for Tropical Medicine in Hamburg, G ermany.

Indeed, many questions remain. Can infected individuals infect others if they are not coughing or showing any other symptoms, and if so, how long is the infectious period? If the virus originated in southern
China, is the disease endemic to that region or can it arise elsewhere? How did food workers, who comprised most of the original cases, become infected? Why does the disease not affect very young children? How long can the virus survive outside the body and remain infectious? Although SARS has aroused a good deal of speculation-a letter to the Lancet from the UK $(361,1832 ; 2003)$ stated that the virus might have originated in outer space-some reliable information is available. The virus is much less contagious than influenza and measles, said Fleischermost cases in China, which has the lion's share of SARS patients, are among healthcare workers and their close contacts, both at home and work. Age and the co-existence of other diseases, such as diabetes, heart disease and hepatitis B, are significant risk factors for death from the virus, said Fleischer.

$T$ he SARS outbreak has also been a major test of the WHO 's ability to deal with emerging infectious diseases and, on most accounts, it has scored well. The WHO 's efforts included activating its Global Outbreak Alert and Response Network (GOARN) and real-time early warning system to filter and analyse worldwide news reports. The WHO sent experts in infectious disease control and protective equipment to hard-hit locales in China when it was allowed to do so-and sooner elsewhereand used its electronic global flu-alert mechanism to set up a virtual network of 11 laboratories. Experts from these centres conducted daily teleconferences to pin down the infectious cause of SARS, share epidemiological information and collaborate to develop a diagnostic test.

It was the WHO that strongly recommended the screening of passengers before boarding aeroplanes, and it issued the most stringent travel warnings in its 55-year history to stem the further spread of the virus. The WHO also urged increased vigilance by airline personnel, resulting in the quarantine of many passengers. At a local level, WHO experts helped to trace and isolate those who had been in contact with infected people, which reduced transmission in urban areas. They also assisted in the adoption of extra safety measures at hospitals in Canada and China.

"Preparedness for an outbreak of infectious disease requires that we learn lessons from past experience," said Zambon. Strong $R \& D$ within public-health structures, investment in diagnostic capabilities, strong links between public health and communities and rapid-response capabilities are paramount, she commented. "In the SARS crisis, we saw a comprehensive and intensive response," Zambon said, adding that the system still needs some improvement to better co-ordinate its epidemiological and molecular diagnostic efforts. Indeed, since the terrorist attacks in the USA in September 2001, and the anthrax letters sent the following month, the problem of detecting and eradicating infectious diseases on a global level has become even more important. The WHO is obviously taking this seriously, and announced in $\mathrm{May}$ that it plans to raise US $\$ 200$ million-half of that by September 2003-to help rebuild China's health infrastructure to aid the country in its fight against SARS. The funds will be used to train health workers, rebuild reporting networks and treat patients.

\section{By the end of May, the outbreak of SARS had cost US $\$ 100$ billion globally...}

At the same time, the United Nations (UN) approved new and broader powers for the WHO. These measures, which still need to be ratified by the UN member states, will enable the organization to establish 24-hour communications with nations and to appoint an official who can take emergency action against a threatening disease. The W HO will use non-official sources of information during an international public-health threat, issue global alerts for such threats, and the WHO's Director General can send an expert team to 
investigate whether a nation has taken sufficient measures to control a disease threat.

\section{And it isthe sameeconomic boom that is now threatened by SARS that, paradoxically, allowed the virus to proliferatein the first place...}

"In a highly mobile society, there is no way to contain a disease unless one considers the problem a global health issue," commented Jessie Gruman, Executive Director of the Center for the Advancement of Health (Washington, DC, USA), a non-profit institute dedicated to translating research into practice and policy. "Infectious disease is no longer regional or owned by the poor; it gets on airplanes and can threaten the rest of the world in days," she said. She hopes that SARS will be "the harbinger that provokes us to reexamine a health research enterprise that relies so heavily on the assumptions of commercial interests to translate its products for the benefit of society."

Indeed, although the technology needed to develop drugs and vaccines against SARS exists, appropriate incentives to bring them to market are lacking. O ne chief scientist of a biotech company noted in The New York Times (27 May 2003) that although his company has extensive experience in developing anti-viral drugs, it does not plan to develop a drug against SARS because it is unclear whether the disease will remain a health threat and therefore result in profits for the company.

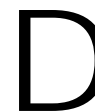

rug development costs money, but so does a pandemic. By the end of May, the outbreak of SARS had cost US $\$ 100$ billion globally, according to the Cambridge Research Institute (MA, USA). And it is the same economic boom that is now threatened by SARS that, paradoxically, allowed the virus to proliferate in the first place, commented Joshua Muldavin, Professor of Asian studies and human geography at Sarah Lawrence College (Bronxville, NY, USA). Muldavin, who lived and conducted field studies in China for more than 20 years, observed that political reform in China during the early 1980s resulted in rapid economic growth but also led to the dismantling of China's extensive public health system, including all health monitoring. As funding for state-run health facilities dried up, many hospitals had to close, and the Chinese public health-care system started to crumble. "W hile China's growing elite can now access advanced health facilities, hundreds of millions of peasants-China's majority-no longer have access to even rudimentary facilities. Where local healthcare is still available, in the current pay-asyou-go system a simple visit to a doctor in a hospital in rural China can cost US \$250-a few dollars less than the per capita income of people in the countryside," Muldavin said.

And SARS is just the tip of the iceberg. In the past few years, tuberculosis cases have quadrupled and AIDS has spread rapidly, not only in China but in many other countries, too. Be it SARS or something else, infectious diseases and the fear they trigger have caused a lot of political unrest and economic instability, which sends out ripples across the world. The solution is not money from W HO or elsewhere, but rather a long-term plan to re-involve nations in healthcare, Muldavin thinks. "The situation requires active state participation well beyond anything currently envisioned. [... ] By depending on the market to provide health care, the Chinese state may have made its most costly blunder yet, one for which we may all pay the price," Muldavin concluded.

\section{Vicki Brower}

doi:10.1038/sj.embor.embor892

\section{Does marijuana havea future in pharmacopoeia?}

\section{Although recent research backs the therapeutic benefits of cannabis, its adverse effects and the risk of addiction push against the legalization of the drug for medical use}

ts ts Latin name in botanical classification is Cannabis sativa L. but most people know it as marijuana, grass, pot, dope or weed, mainly when referring to its recreational use. Recently, this green plant, which grows up to five metres, has acquired a new name: 'the aspirin of the new century', reflecting hopes that cannabis could be used to treat a variety of ailments, ranging from migraine to cancer (Baker et al., 2003). By discovering how the active ingredients of the plant exert their effect on the human metabolism, scientists think that cannabis could have great potential for the development of new drugs. But whether or not the beneficial effects of marijuana are further supported by biomedical research, those counting on them will nevertheless have to face the legal aspects of using the drug in their countries. Indeed, the negative aspects of the plant, mainly the risk of addiction, are the reasons why most countries have outlawed the growth, possession and consumption of cannabis. The debate about the health benefits of cannabis is thus lost in a bitter clash between authorities that enforce strict laws against its use and proponents pushing for its legalization.

The many beneficial aspects of cannabis are not a new discovery-the plant has a long tradition in medicine that originated in oriental and Middle Eastern countries. The Chinese documented its medicinal value more than 4,000 years ago, using seeds, leaves and sap as sedatives or painkillers and to treat fevers, nausea and ulcers. Ancient herbalists made unguents for burns and other wounds from its roots. Galen, and other physicians of the classical and Hellenistic eras, also noted cannabis as a remedy, and the Arabs started using the plant as early as the mid-1200s. Although there is evidence of cannabis use in Europe from the thirteenth century, after Marco Polo returned from his journey to the east in 1297, its medical use became more popular in the nineteenth century, when the British physician William B. O'Shaugnessy brought back an account of the remarkable effects of this plant from India. Even Q ueen Victoria is said to have sipped marijuana tea prescribed by her court physician to treat menstrual cramps. 